Article

\title{
Sustainable Energy Development: The Key to a Stable Nigeria
}

\section{Kalu Uduma ${ }^{1,2, *}$ and Tomasz Arciszewski ${ }^{2,3}$}

1 Alpha-Solar LLC, 19962 Renfrew Road, Detroit, MI 48221, USA

2 Civil, Environmental and Infrastructure Engineering Department, The Volgenau School of Information Technology and Engineering, George Mason University, Fairfax, VA 22030, USA; E-Mail: tarcisze@gmu.edu

3 The ASCE Global Center of Excellence in Computing, Fairfax, VA 22030, USA

* Author to whom correspondence should be addressed; E-Mail: ku1 @alphapv.com; Tel.: +1-248-894-8747.

Received: 20 April 2010; in revised form: 8 May 2010 / Accepted: 17 May 2010 /

Published: 3 June 2010

\begin{abstract}
This paper proposes the use of sustainable energy systems based on solar and biomass technologies to provide solutions to utility challenges in Nigeria and acute water shortage both in rural and urban areas of that country. The paper highlights the paradoxes of oil-rich Nigeria and the stark reality of social infrastructure deprivations in that country. Perennial power outages over many years have translated to the absence of or poorly-developed basic social infrastructures in Nigeria. The consequences of this lack have been an increase in abject poverty in rural and urban communities as well as the erosion of social order and threats to citizen and their property. This paper proposes the adaptation of two emerging technologies for building sustainable energy systems and the development of decentralized and sustainable energy sources as catalyst for much-needed social infrastructure development through the creation of Renewable Energy Business Incubators, creative lending strategies, NGO partnerships and shifting energy-distribution responsibilities. These changes will stimulate grassroots economies in the country, develop large quantities of much needed clean water, maintain acceptable standards of sanitation and improve the health and wellbeing of Nigerian communities. The proposed strategies are specific to the Nigerian context; however, the authors suggest that the same or similar strategies may provide energy and social infrastructure development solutions to other developing countries as well.
\end{abstract}


Keywords: sustainable energy; social infrastructure; solar energy; bio-energy; OPEC; NGO; Renewable Energy Business Incubators

\section{Introduction}

Nigeria's chance to raise the standard of living for its citizens and stabilize its social, economic and political systems lies in its commitment to increase energy output and utilization starting at the grassroots level. However, Nigeria cannot afford to indulge in the traditional exploitation of depleting energy sources such as wood and fossil fuel. The new paradigm of global environmental sensitivity and the reality of dwindling forest and oil reserves demand that Nigeria's much-needed energy sources be diversified. The country must focus on the development of renewable and sustainable sources. Application of sustainable energy systems as a means of developing distributed and decentralized social infrastructures in Nigeria will stimulate grassroots economic development as well as "stem the prevailing state of crime, provide access to sufficient quantities of clean water and maintain acceptable standards of food and goods production, sanitation, and health" [1] for that country's citizens. These factors are part of the hierarchy of basic human needs that gauge the well-being of any community and are key elements to consider for a stable Nigerian nation. Sustainable energy development in Nigeria is the key to the stability of the country, in terms of a viable economy, social order and political stability.

In order to benefit from the energy revolution, however, a systematic adaptation process of new sustainable energy technology must be developed. A suggested process that will benefit all of Nigeria's citizens is one that:

- Identifies the sustainable energy system enterprises that will create maximum benefit at the grassroots and community level;

- Prioritizes the effectiveness of those sustainable energy enterprises;

- Identifies the distributed social infrastructures that will benefit from the identified sustainable energy sources; and

- Recommends a model that will develop the appropriate sustainable energy enterprises as well as cultivate a sense of ownership by the beneficial community through education support in the area of resource management.

A key facilitating factor in realizing the benefits of the above components is the solicitation of assistance from and partnership with Non-Governmental Organizations (NGOs) with proven technical and management expertise in new energy sources such as solar, wind, and biomass. These experts will (1) help to adapt the new technologies to the local environment; and (2) develop local experts who will manage the new technology enterprises. In turn, the patron NGOs will benefit as well, in a global sense, from a stable Nigerian nation.

This paper also recommends the establishment of "Renewable Energy Business Incubators" in few select Nigerian research institutions. The overall objective of these centers will be to develop a new technical culture in Nigeria and educate Nigerians on its benefits. The centers will: 
- Stimulate solar energy and other renewable energy inventions and innovations at technical colleges and universities through courses focused on inventive design in the context of renewable energy;

- Coordinate the development of inventive ideas in sustainable energy between Nigerian technical colleges and universities;

- Manage the innovation process, i.e., the transformation of ideas into commercial products and processes;

- Solicit financial and logistic support for inventors to develop their patentable/patented inventions for mass production and marketing.

\section{Background}

One significant factor that is generally recognized as the best indicator of any nation's level of development, industrial strength and wealth is the amount of energy that is available and used by that country. This is because, in most cases, there is a strong statistical correlation between a country's energy consumption and its economic output [2]. The reason for this relationship is the reliance of the majority of the world's economic activities on the availability of energy [2]. Energy shortage may sound paradoxical in a major oil-producing nation such as Nigeria. However, acute energy shortages for many years in this country have led to perennial and regular electric power outages, with serious consequences for economic development, citizen safety and the quality of life for its people.

Over the past twenty years, power outages have transformed the once-vibrant Nigerian nation from a country whose economic potential was clearly evident to a nation whose economic life is now precariously reliant on the volatile and dwindling fossil fuel market. Over the last two decades, population surges in the cities have translated into overwhelming demands on electricity [3]. Unfortunately, the absence of any concise government policy or strategy for the diversification of Nigeria's energy resources has resulted in the only source of electric power supply system in the country being stressed to maximum capacity. This system can no longer sustain its people nor contribute towards the economic development of the country. The consequences have been the neglect of grassroots economic development, erosion of social order and threats to citizen and their property.

During this time of economic meltdown, growing poverty and the lack of opportunities for young people both in the cities and in rural areas have been the major contributing factors to the breakdown in social order and increased political instability and criminal activity. It is little wonder that safety is now at the top of the list of citizens' concerns in Nigeria. Unlit streets, businesses and homes have become easy targets for armed robbers. Families and businesses who can afford them have resorted to generators for their electric-lighting needs. These generators are not only expensive to maintain, but are also sources of undocumented but potentially-huge increases in air and noise pollution in Nigerian cities. In order to protect the generators from theft, families typically cage their units within their homes. The result is a dangerous exposure of family members to carbon-monoxide poisoning as well as irritating noise pollution. Cases of families who went to bed at night and did not wake up the next morning because of carbon-monoxide poisoning are common in newscasts across the country.

Even in the cities that traditionally were the foci of economic activities, any new business start-ups must now first budget for a massive investment in reliable sources of electric power and clean water, 
besides making arrangements for property safety. These extra investments have become challenging hurdles that often discourage new businesses and also threaten existing one.

A viable grassroots economy, social order and political stability in Nigeria will be greatly enhanced if sustainable energy sources are developed and used to supplement Nigeria's current energy supply. Applications of these sustainable energy sources will catalyze the development of decentralized social infrastructures which are key for the stimulation of economic development and the curbing of social ills.

\section{The Paradox of Energy Shortage in Oil-Rich Nigeria}

Records show that Nigeria is the largest oil producer in Africa and possibly one of the six largest exporters of oil in the world. The country is also a key member of OPEC. With this oil background, it is indeed ironic that power shortages occur with such frequency in the country. Some of the explanations that have frequently been volunteered for this endemic energy shortage in Nigeria are [4]:

- Gross resource mismanagement;

- Persistent ethnic violence and eruption/vandalism of oil supply lines in the predominantly oil-producing regions of Nigeria;

- Negligence by subsequent Nigerian governments to invest in the energy sector and adapt energy development to local need;

- Poor distribution systems and even poorer maintenance of the few existing distribution systems. (It is estimated that "of the 79 power plants in the country, only 19 are operational");

- Sabotage and thefts of transmission lines which cause wide-spread power outages;

- Gross incompetence of politically-appointed power sector managers and poorly trained workers;

- A vulnerable grid layout that makes it easy for people to connect to their homes and even business without meters; and finally

- The well-documented endemic corruption in many other sectors of the Nigerian beaurocracy.

The best description of the current situation was reiterated by [4] Nenadi Usman, Nigeria's former finance minister. He underscored the problem recently when he said, "South Africa generates 40,000 MW of electricity for her 45 million people. Meanwhile Nigeria, which has 140 million people, has barely 4,000 MW of capacity, and her production costs are five times higher" [4].

Most businesses in Nigeria, large and small, end up relying on the generator for electricity to power their businesses. MTN - the South African mobile phone company and the largest mobile phone supplier in Nigeria - is estimated to "have installed 6,000 generators to supply its base stations for up to 19 hours a day. The company spends $\$ 5.5$ million a month on diesel fuel to run the generators" [4].

\section{Viable Sustainable Energy Options}

The consequence of the energy shortage on Nigeria has been a stifling of economy opportunities and growth at the grassroots level. Perennial power outages stifle manufacturing and infrastructure 
development in the cities. Absence of electric power development in most of Nigeria's rural communities forces millions of families to rely on firewood for cooking, which in turn, impacts the environment. A documented [5] trend estimates that over 300,000 hectares of deforestation occur per year in Nigeria due to a combination of rapid growth in the timber industry and domestic firewood dependency. Africa as whole is estimated to have lost 64 million hectares of forest between 1990 and 2005, more than any other continent, and firewood-gathering was the major cause of this depletion [5]. In addition, as stated earlier, millions of generators in both the cities and rural areas add to the stress on the environment. What is urgently needed to stem the assault on the environment, reverse the growing poverty trend and improve sanitation and the quality of life for the people is an investment in sustainable energy alternatives.

Two viable and sustainable energy technology enterprises that will have immediate positive effects on the lives of Nigerian citizens are (a) decentralized solar electric energy generation and (b) biogas generation through the development of biomass technology. These two sources of sustainable energy will not only improve the lives of urban and rural communities but will also be crucial in providing the energy needed to pump and purify water. This infrastructure is currently lacking or inadequate in most urban and rural communities of Nigeria, with catastrophic consequences so far. The development of wind energy source systems may become an option whose feasibility depends on the advancement of the relevant technology. Wind maps [6] that includes wind velocity distribution in Nigeria shows that rare winds may not sustain wind turbine at moderate pole heights. However, at other heights and using different technology, wind systems become very feasible.

\subsection{Opportunities for Distributed Solar Electricity Generating Enterprises}

Nigeria is squarely located in the tropics, with its land mass stretching between latitudes 5-degrees south and 15-degrees north of the equator. As a consequence, the country enjoys abundant amounts of sunshine. In fact, relevant studies on the potential and viability of solar energy sources in Nigeria show that Nigeria has nearly 290 days of sunlight in a year. The average solar insolation in Nigeria is estimated to vary between $4.0 \mathrm{KWh} / \mathrm{m}^{2} /$ day at the southern coasts to $7.0 \mathrm{KWh} / \mathrm{m}^{2} /$ day at the northern coasts of the country [7]. The daily average is estimated at $5.5 \mathrm{KWh} / \mathrm{m}^{2} /$ day. The availability of abundant sunshine is a positive indicator that Nigeria is an ideal candidate for investment in solar energy resource development.

The opportunities offered by decentralized rural community solar powered electrification programs, as shown in Figure 1, have been well documented [7]. For Nigeria, these benefits include but not limited to community water pumping; Figure 2, enhanced health care delivery to rural areas and remote villages, exposure to modern education technology and lighting. Solar energy sources could therefore enable the development of social infrastructures that will:

- Greatly enhance the health and wellbeing of rural communities;

- Catalyze the development of mom-and-pop cottage businesses; and

- Stem urban migration, which in itself will help to decongest the cities. 
Figure 1. Rural and urban solar powered electrification [8]. (Reproduced with permission from "Solar PV Powered Street Lights at Chittagong Hill Tracks Region in Bangladesh"; published by "Renewable Energy Education \& Information Network (REEIN)", 2008).
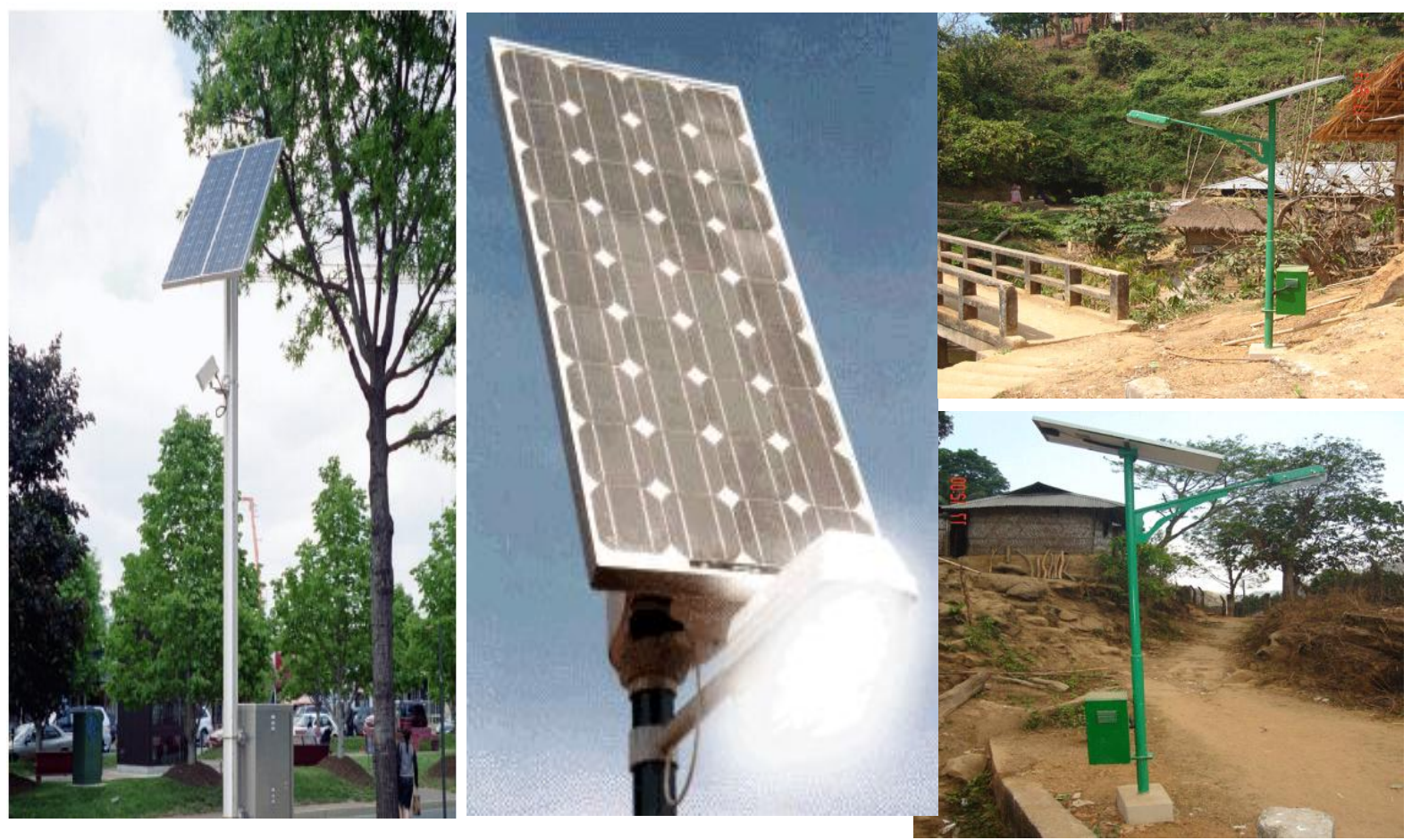

Figure 2. Solar powered water borehole pumping [9]. (Reproduced with permission from "Solar (PV) Water Pumping: Practical Answers to Poverty"; published by "Intermediate Technology Technical Group", 2007).
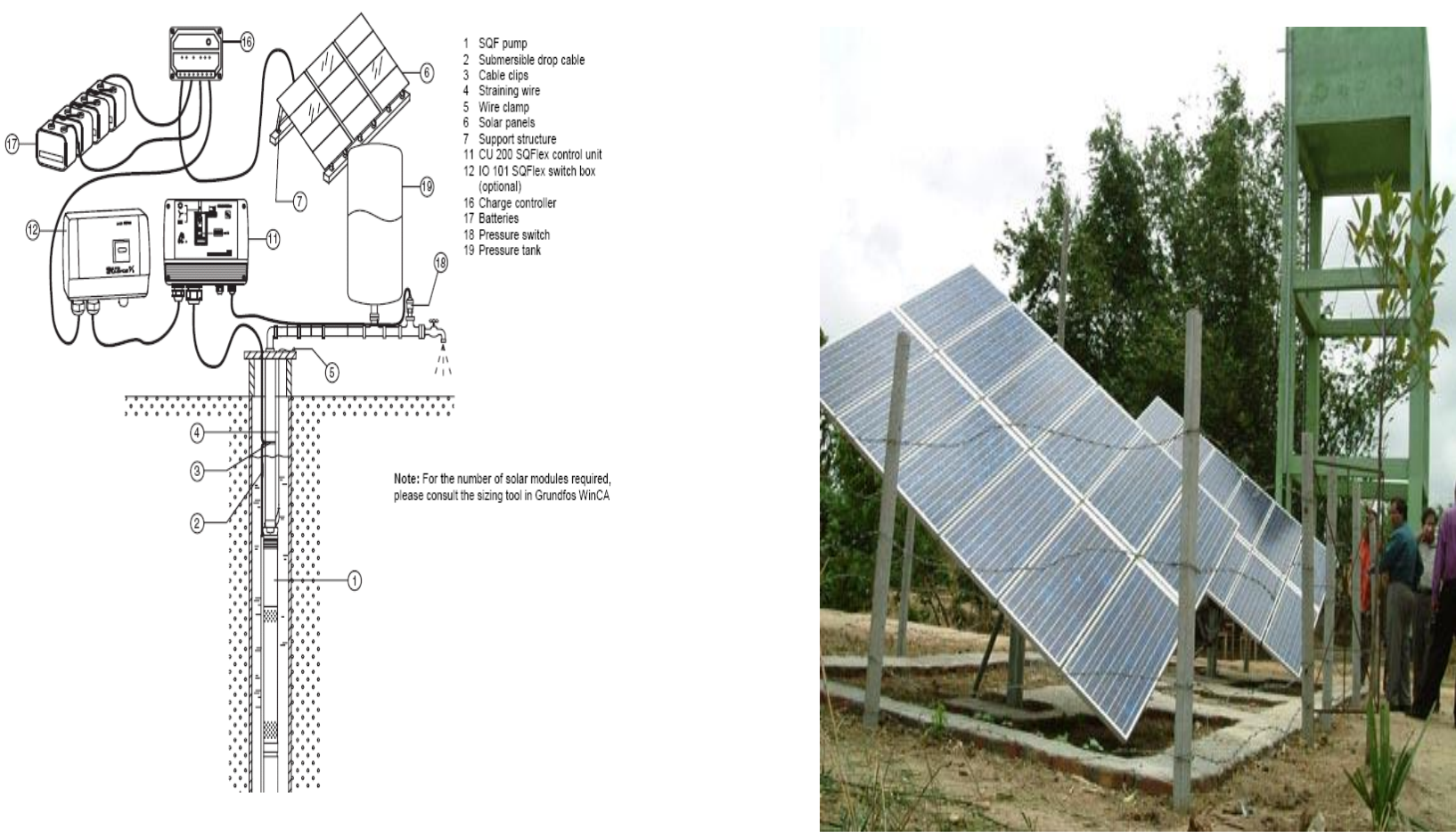


\subsection{Opportunities for Biomass Technology Enterprise Development}

For a bio-dependent culture, it is not a surprise that much of the rural community's waste is biodegradable. This situation presents great opportunities to employ biomass technologies, such as "digesters" to generate biogas as a sustainable byproduct. An example of a Chinese biomass dome digester [10] is shown in Figure 3. One byproduct of biomass technologies is biogas. Biogas is described as [11] "a combustible mixture of gases produced by micro-organisms when livestock manure and other biological wastes are allowed to ferment in the absence of air in closed containers". The major constituent of biogas is methane.

Figure 3. Biogas in China [10]. (Reproduced with permission from"Biogas in China"; published by "Institute of Science in Society (ISIS)", 2006).

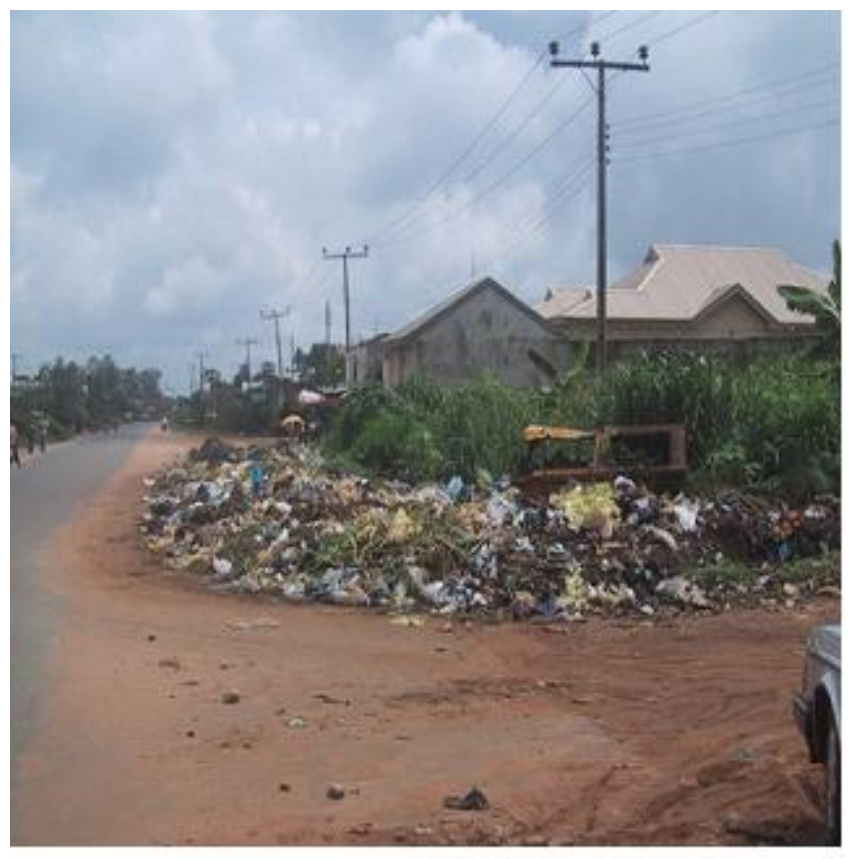

Urban Trash

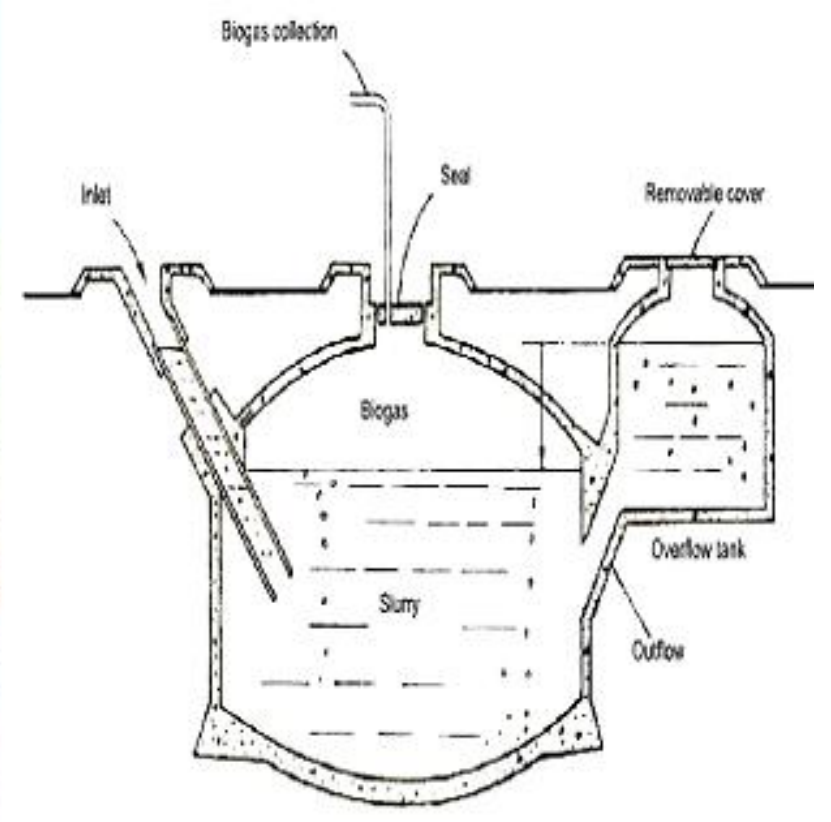

Chinese Biomass Dome digester

In Nigeria, it is common for each village community to have its "ugwufiri" - the village open landfill, where for many years, the village community wastes are dumped. There may be two or more such open landfills in a given area, depending on the population of the village. The composition of the biological material in a typical landfill are manure from domestic animals (chicken, goat, pig, etc.), excreta from children who are too young to use the village open-air toilet, stalks and straw of crops and vegetables and fruits. Over the years, those untreated open landfills become health hazards, especially with their proximity to villages. With the use of biomass technologies, these hazards can turn into viable energy resources.

Investment in biomass technology enterprise development will be revolutionary and will transform the urban and rural communities of Nigeria from the depths of filth and trash to a healthy and sanitary country. At the same time, it will generate sustainable biogas that will be used to power gas generators for the everyday community's energy needs. Biomass technology will simply transform the community from one of "waste" to one of "wealth". 


\section{Challenges for Sustainable Energy Technology Development in Nigeria}

Needs and availability of raw material are sadly not always guarantors of technology development. This is true in this case for sustainable energy development in Nigeria. The following are recognized potential challenges to the development of sustainable energy technology in that country:

- Lack of related technical skill: Historically, a major reason for failed renewable energy system projects has been the absence of know-how transfer of the new technology to individuals in the communities that received them. The executors of new technology often overlook the need for local technical training, maintenance service expertise development, user education and awareness. Renewable energy technician training will be absolutely necessary for any renewable energy project to be successful. Builders will need education in renewable energy construction techniques and the public psyche will need to be shifted to adapt their lifestyles to a changing energy system [12]. Trades schools, technical colleges and universities will need to be prepared and equipped to support the transition to the new energy system as well.

- Uncertainty of finance sources: Renewable energy technology is still expensive at its current stage of development, even to governments. For rural communities and individuals, the cost of owning a self-sponsored renewable energy system is simply cost prohibitive. Short of a donor-developed project by an NGO, an innovative financing approach will be needed to implement a renewable energy based infrastructure in the rural communities where the need is the greatest.

- Orderly implementation of the new energy systems: This is important in order to cut down on sloppy projects and "quackery". Typical of any newly introduced social apparatus, the excitement of new energy technology coupled with the yearning of citizens for a steady power supply is attracting a myriad of "quacks" into the renewable energy development business. One of the greatest impediments to adoption of the new energy system will be disappointed citizens who are burnt with failed renewable energy projects executed by illegitimate businesses wanting only to make a profit.

Poor resource management and lack of commitment by various levels of government to invest in energy development are also real challenges that may mitigate a successful implantation of any sustainable energy technology.

\section{A Viable Sustainable Energy Enterprise Development Model}

To create a sustainable energy development model, it is suggested that a triad joint research synergy involving local and experienced foreign institutions and a committee of local and foreign experts be created. The committee of experts will bridge and coordinate research and development activities of both resident institutions, provide practical implantation and adaptation of research results to local environment and develop local technical skill in order to preserve and maintain the implanted project.

Both the foreign and local research institutions will co-establish and run a renewable energy research, develop and run business incubator centers in the Nigerian resident institution. The general 
objective of the research centers will be to develop systems for adapting sustainable energy technologies to the local environment, including:

- Research and development of local design load requirements for sustainable energy support structures;

- Research and development of novel photovoltaic (PV) system mounts and support structures adaptable to the typical rural community construction;

- Research and identification of abuse factors that affect survivability of sustainable energy systems in the local environment;

- Research and develop foundation design standards for the sustainable system support structures in the typical clay-dominant southern Nigerian soil;

- Design and develop construction standards for sustainable energy systems structures consistent to other local environments; and, above all,

- Institute certification programs and steps for licensing prospective renewable energy practitioners so that public-end users will be assured that their investments are being executed by certified renewable energy development professionals.

The objectives of the business incubator aspect in the center would be to:

- Stimulate solar energy and other renewable energy inventions and innovations;

- Encourage and develop inventive disciplines in renewable energy at technical colleges and universities;

- Coordinate inventive and innovative ideas in sustainable energy from other local technical colleges and universities; and

- Solicit financial and logistic support for inventors to develop their patentable/patented inventions for mass production and marketing.

The foreign research institution will:

- Be a conduit for the state-of-the-art research tools and technology needs of the center from advanced countries to the local centers;

- Provide technical resource management skills; and

- Infuse trust, credibility and transparency to the activities of the centers. These factors are especially relevant in order to attract serious investors from outside of and within Nigeria. The foreign research. institution will also assist in attracting funding and relevant technical skills from outside the local center.

The local research institution will:

- Share custody of the research results with the foreign research institution;

- Coordinate local logistics necessary for successful activities of the local center;

- Identify the necessary research areas that are relevant to the environment;

- Identify key potential local investors; and

- Be a liaison between the center and local and national regulations. 


\section{Feasible Sustainable Energy Enterprise Financing Models}

Two traditional and two alternative but feasible financing models are identified by the authors.

\subsection{NGO Donor Projects}

NGO donor projects are still the source of financing of most renewable energy systems in rural areas of developing countries today. Unfortunately, however, donor projects have frequently been short-lived due to neglect. It has been sadly observed that communities that benefit from donor projects lack a sense of ownership and commitment to the project since they did not pay for it. The authors suggest that a better option would be for NGOs to become part sponsor/patron of the suggested triad joint research synergy. This will infuse greater credibility, accountability and focused management of sustained energy resources and the derived social infrastructures in target communities.

\subsection{Government-Funded Renewable Energy Projects}

The task of developing and incorporating sustainable energy systems within Nigeria is too important to rely only on the gratitude of NGO donors alone. The different levels of Nigerian government need to understand the importance of energy factors in economic development and subsequently in social and political stability and in the overall well-being of its citizens. Funding allocations for research and development of new energy systems needs to be embraced by the government and this action must include the removal of energy generation and distribution autonomy currently given to the Power Holding Company of Nigeria (PHCN). The complexities of energy generation and distribution have simply become too overwhelming for one entity to handle. Decentralized and distributed energy policy holds a great potential for stabilizing Nigeria's electric power system.

\subsection{Individual/Community Contracts with Government Sponsored Energy Investment Banks}

The Federal government of Nigeria can sponsor and encourage select investment banks to specialize in alternative energy development funding projects. The government will loan seed money to such select banks who will then conduct research on which individual, entity and community energy projects to give loans to. Loan servicing is a critical function of commercial banks. Select banks will work out loan allocation and debt collection details with their clients. The government should not run such lending institutions but will have a share of profits derived from the energy investments generated by the banks. At the same time, the initial principal loan will be paid back to the government. In an honest transaction, the government will not lose any money.

\subsection{Loans from Energy Investment Banks to Compete with Government Sponsored Banks}

A culture of new energy systems could be sown into the psyche of the business community enough to attract individual banks to start specializing in energy investment. The authors actually find it 
surprising that after all these years of energy-induced hardship in Nigeria, no commercial bank has shown innovation in investment to the sustainable energy commodity. One hindrance may be the concern of legal conflicts with the existing energy generation and distribution monopoly given to the PHCN. While smaller investors may escape the eye of the Power Holding Authority, commercial banks may not fare so favorably. This is another reason why the government ought to ease this power generation and distribution monopoly. With this burden lifted, banks may be more ready to invest in sustainable energy development.

Investment banks may still be held back by the following commonly held perceptions that:

- Nigerians do not pay their utility bills. This may be borne out of frustration by Nigerians with the inconsistent utility availability given to them. No one will gladly pay bills for the services they do not receive.

- The new energy systems are costly and unaffordable to the rural community. A well-coordinated and structured loan repayment may convince even the poorest family to buy into the new energy system. Solar power systems have long durability. With that longevity, loans can be structured and spread over many years to make it affordable to citizens. Currently, Nigerian families spend a good portion of their income on kerosene and diesel gas to power their lamps and generators. Loans structured to the monthly expense level of kerosene and generators will most likely be a great attraction, especially when the clients begin to appreciate the stability and availability of their new and clean power systems.

Finally, energy investment banks will be a great competitor to government-sponsored energy investment banks. A healthy competition will enhance service efficiency on all sides.

\section{Funded Sustainable Projects by Community Offsprings in Diaspora}

The strong affinity of immigrant Africans living in the West to their "home" countries is demonstrated by their continuous participation in and contribution to development efforts going on in their respective original communities. This affinity offers a great opportunity to galvanize immigrant groups in funding renewable energy system projects that will enhance and catalyze grassroots economic and social infrastructure developments in their respective home communities, improve the standard of living for those still in those community and bring comfort for vacationing offspring and their foreign-born children. It is estimated that Nigerians living in the U.S. send a million dollars or more home to their relatives and to support various projects in their original local communities. A well-coordinated effort may harness these great assets to support renewable energy projects that will help bring stable and clean electric lighting, clean water and improved sanitation to Nigerian villages. This, of course, will help to improve good health, stimulate local economy, stem growing crime and provide safety for those living there as well as visiting relatives.

There is little doubt that Nigerians in the U.S. who already raise funds to build maternity homes and health centers in their local communities will have no difficulty seeing the need to bring solar electricity to light up and preserve the life-saving equipments in those centers. 


\section{Conclusions}

The economic and social opportunities that sustainable energy systems can bring are significant attractions for various private and federal organizations in Nigeria to invest aggressively in the new systems. However, an orderly adaptation process to the new energy system must be followed. The authors have proposed such a process. They have:

(a) Identified solar powered electric energy and biogas generation through biomass technology development as systems enterprises that will create maximum benefit at the grassroots level in both the rural and urban communities of Nigeria;

(b) Recommended as a priority the need to modify the current energy generation and distribution monopoly in Nigeria and allow decentralized investment and development of sustainable energy systems;

(c) Recommended the creation of a triad joint research synergy between a foreign research institution, two or more research institutions in Nigeria and a renewable energy development professional who will bring about the execution and implantation of research results into practice;

(d) Identified the distributed social infrastructures that will benefit from the identified sustainable energy sources; and

(e) Recommended financing models that will help stimulate sustainable energy development and make it affordable to citizens.

The authors have also recommended the establishment of Renewable Energy Business Incubators at several select research institutions in Nigeria. The overall objective of the Business Incubators will be to develop renewable energy technology and its benefits and create a technical culture in Nigeria. The centers will (1) stimulate solar energy and other renewable energy inventions and innovations, (2) develop academic courses on inventive design in the context of renewable energy at technical colleges and universities, (3) coordinate inventive and innovative ideas in sustainable energy from other local technical colleges and universities, and (4) solicit financial and logistic support for inventors to develop their patentable/patented inventions for mass production and marketing.

Finally the authors recognize how economic trends in the world trace their roots to local instabilities in many countries such as Nigeria and how this destabilization has ripple effects in the global economy. The authors therefore believe that the world also has a stake in a stable and secure Nigerian nation that the investment and development in sustainable energy systems can bring.

\section{References}

1. Koppinger, P.; Gardner, S.; Thorpe, E.; Vutz, C. Renewable Energy: Potential and Benefits for Developing Countries-Proceedings of a Conference Organized by the European Office of the Konrad-Adenauer-Stiftung and the East-West Institute, Brussels, Belgium, 28 February 2007; Konrad-Adenauer-Stiftung (KAS): Berlin, Germany, 2007.

2. Boes, E.; Taylor, R. Understanding U.S. Strategic Interests in Expanding Renewable Energy Systems Worldwide-Summary of the Third NREL Energy Analysis Forum, Washington, DC, USA, 11-12 June 2003. 
3. Nwaka, G.I. The urban informal sector in Nigeria: Towards economic development, environmental health, and social harmony. Global Urban Development Magazine, May 2005.

4. Lawal, L. Lights out for oil-rich Nigeria. Fortune-Energy Shortages, July 2008.

5. Kersten, I. Urban and rural fire wood situation in the tropical rain-forest of south-west Nigeria. Energy. J. 1998, 23, 887-898.

6. Map of Mean $80 \mathrm{~m}$ Wind Speeds for Year 2000; Available online: http://www.stanford.edu/ group/efmh/winds/global_winds.html (accessed on 1 December 2009).

7. Freling, R.; Lahl, J. Renewable Energy Technology: Optimizing Energy Sources for the Development of Millennium Project Villages; Solar Electric Light Fund (SELF): Washington, DC, USA, 8 July 2005.

8. Solar PV Powered Street Lights at Chittagong Hill Tracks Region in Bangladesh; Available online: www.reein.org/solar/streetlights/ (accessed on 1 December 2009).

9. Solar (PV) Water Pumping: Practical Answers to Poverty; Technical Brief; Intermediate Technology Technical Group: Warwickshire, UK, 2007.

10. Li, K. Biogas in China; Institute of Science in Society (ISIS): London, UK, 2006; Available online: http://www.i-sis.org.uk/BiogasChina.php (accessed on 1 December 2009).

11. Kapadia, K. Productive Uses of Renewable Energy: A Review of Four Bank-GEF Projects; Consultant Report to World Bank; World Bank: Washington, DC, USA, 2004.

12. Barnes, D.; Floor, W. Rural energy in developing countries: A challenge for economic development. Ann. Rev. Energy Environ. 2006, 21, 497-530.

(C) 2010 by the authors; licensee MDPI, Basel, Switzerland. This article is an Open Access article distributed under the terms and conditions of the Creative Commons Attribution license (http://creativecommons.org/licenses/by/3.0/). 